\title{
Serving Up Harm: Systemic Violence, Transitions to Adulthood and the Service Economy
}

\begin{abstract}
This chapter extends the zemiological gaze into contemporary labour markets to contemplate harm within the service economy. Data drawn from an ethnographic study of service work complements an ultra-realist framework and explores connections between the depth structures of neoliberal global capital, transformed working environments and subjectivity. Ultrarealism provides an explanatory frame for absences as well as presences; the absence of stability, protection and ethical obligation to the other characterise occupations organised around targets, productivity and affective labour. Under these conditions, systemic and subjective harms are visible, raising questions about both the normal functioning of a sector essential to the service of consumer capitalism and the working experiences of young people negotiating a path towards adulthood whilst engaged in stressful, insecure and low-paid work.
\end{abstract}

Biography - Anthony Lloyd is Senior Lecturer in Criminology and Sociology at Teesside University. His research looks at reconfigured labour markets under neoliberal global capital and thus far has focused on call centres and the service economy. The connection between the sociology of work and labour markets, identity and subjectivity, and the field of zemiology and social harm forms the basis of his current research.

The emerging body of literature on social harm affords new opportunities to look critically at the social landscape in post-crash Britain (Yar 2012; Smith and Raymen 2016; Pemberton 2015). Zemiology offers new directions in fields such as crime (Hillyard and Tombs 2004), climate change (White and Heckenberg 2014), and leisure (Smith and Raymen 2016). Less frequently, the zemiological gaze has been brought to bear on the workplace (Tombs 2004; Tombs and Whyte 2007; Scott 2017). These works often highlight harmful conditions in relation to physical well-being and the absence of effective health and safety regulation (Tombs and Whyte 2007). This chapter presents a new contribution to harmful working by linking an emerging ultra-realist schema (Winlow and Hall 2016; Hall and Winlow 2015) with the structural conditions of employment and experiences of workplace culture within the service economy. The empirical data, which drives the harm discussion within this chapter, underpins a number of other publications in relation to the service economy (see Lloyd 2012, 2013, 2017a, 2017b, forthcoming). Specifically, this chapter will identify a shift from job security towards job flexibility that has marked significance for employees within the service economy, including the erosion of stability. Within a realist framework, absences matter as much as presences; the absence 
of stability, in employment conditions, working conditions, and ontological security, impacts young people in their quest to locate a stable sense of purpose and place as they transition to adulthood.

A political economic shift from production and manufacturing toward consumerism reconfigured Western landscapes from the 1980s onwards (Harvey 2005), and propelled the service economy from the periphery to the centre of UK labour markets. Between 1971 and 2008, Teesside in the UK (the site of the long-term ethnographic study of the service economy underpinning this chapter) lost 100,000 manufacturing jobs, largely in steel-making and petrochemicals, which were replaced by 90,000 jobs in service industries (Shildrick et al 2012). This was indicative of a sweeping shift across the UK, USA and parts of Europe as burgeoning consumer markets presented opportunities for expansion in retail and leisure services, the night-time economy and other customer service functions (Lloyd 2013). In a culture that increasingly demonises those out of work (Shildrick et al 2012), paid employment is today regarded as a positive, with scant regard for the actual conditions of employment. Media scrutiny has highlighted individual operators such as Sports Direct or Amazon as distinctly beyond the pale in terms of working conditions and management practices, yet those who direct their ire at Mike Ashley have often failed to let their gaze drift beyond their target. Sports Direct and Amazon are not rogue operators in an otherwise proficient and unproblematic stratum of the labour market but instead represent the normal functioning of the late capitalist service economy.

\section{Ultra-Realism and Social Harm}

If zemiology is to carry weight as an explanatory frame, it must have solid foundations (Hall 2012). An emerging ultra-realist schema is venturing to thrust criminological and sociological thought beyond the ascendant empiricism directing the discipline, beyond the administrative and pragmatic wings of social science seeking efficient governance of the current political economic order, and beyond the flaws within critical realism (Hall and Winlow 2015). Depth structures have causative effects on individuals and the socio-cultural logic of society (Bhaskar 2010); empiricism evidences what we can see but fails to contemplate the causal influence of the intransitive realm of deep structures upon the quotidian reality of individuals and communities (Winlow and Hall 2016). In this sense, critical realism offers a positive theoretical route towards grasping the relationship between concrete events, lived experiences and the deep structures of society (Collier 1994).

Ultra-realism follows this line of enquiry yet eschews the critical realist interpretation of subjectivity (Winlow and Hall 2016). Rather than endorse belief in a natural human essence, where the subject is inherently 'good', ultra-realism subscribes to the Lacanian-Žižekian explication of subjectivity (Žižek 
2000). The subject is a non-essential void, an unconscious complex of pre-social drives and desires capable of both good and evil (Hall and Winlow 2015). This 'transcendental materialist' interpretation of subjectivity (Johnston 2008) suggests that the non-essential subject actively solicits an external symbolic order as a defence mechanism to provide internal meaning to external stimuli. The inherent plasticity of the brain ensures neuronal receptors adapt and reconfigure to equip the subject with the values, norms, language, comportment and symbolic framework necessary to exist in the world (Winlow and Hall 2013; Johnston 2008; Žižek 2000). In practical terms for this discussion, the symbolic order emanating from the depth structures of ideology and political economy influences the subject who possesses active agency to reproduce existing material and symbolic structures or to work to change them. In order to discern conditions within the service economy, an ultra-realist perspective contemplates the relationship between the individual, the workplace and the depth structures of political economy and ideology, which corresponds with Žižek's (2008) injunction to equate subjective and symbolic violence as symptoms rather than causes. The generation of harms, by virtue of the system and its normal functions, presents a constructive line for analysis. A critical facet of ultrarealism is its capacity to interpret absences as well as presences; in pursuit of the causative effects that generate harms within the service economy, the absence of something is just as causal as a presence (Winlow and Hall 2016).

\section{Absences}

Absences, within ultra-realism, have a probabilistic causal influence on our lives (Hall and Winlow 2015). Neoliberal restructuring does not mechanically cause harm, but the systemic violence at the heart of capitalism is visible through the subsequent absences of, for example, welfare regimes that forestall material deprivation or job security that provides a measure of stability. This negativity omits any form of positive transformation in material and social conditions but still retains the transformative potential to reshape interpersonal connections and working cultures. The post-war settlement enclosed a regulatory jacket around the generative core of capitalism to yield a degree of stability and durability at a material level; job security and propitious employment conditions were attained via legislation and union bargaining (Harvey 2005). Job security brought a modicum of compensation for stringent and often physically dangerous working conditions or mistreatment by management or other co-workers. This is not to romanticise industrial capitalism; harms were still inflicted at a systemic, symbolic and subjective level, yet the job security provided during the post-war settlement permitted the individual subject to situate their identity in a community, class, or occupational culture (see Lloyd 2013). 
The neoliberal 'restoration' (Harvey 2005; Badiou 2009), exemplified by ideological exhortations towards free-market principles of flexibility, freedom and choice represented a systematic puncturing of welfare's regulatory jacket (Whitehead and Hall 2017, forthcoming). Institutions previously exempt from market principles underwent a reorganisation of institutional culture and drivers that resulted in an ideological, symbolic and material shift in practice and the solicitation of market principles (Whitehead 2015). The faith in market mechanisms to efficiently order all facets of social life indicated the unshackling of capitalism's generative core. Economic stagnation in the 1970s was met with howls of derision at policy grounded in regulatory frameworks formulated to secure greater fairness and equality; by unleashing the free market, deregulating and re-regulating industries in order to facilitate market proliferation and autonomy, the social, cultural and economic landscape transformed dramatically. Since the financial crisis, neoliberalism has doubled-down. Despite its apparent flaws, market principles have diffused into the public sector whilst private firms maintain their pursuit of efficiency, productivity and growth. To further these ends, regulation on working environment and employment protections have been systematically reconfigured and eroded (Streeck 2016). Within the service economy, these absences are distinctly visible.

\section{The Absence of Stability}

The shift from job security to job flexibility is exhaustively recapitulated within the literature (Beck 2000; Standing 2011; Kalleberg 2009). Sennett (1999) articulates the 'corrosion of character' evident in the shift from established working environments and job security that affords the individual the long-term scope to mould durable character and identity, towards a variable pattern of working that focuses unreservedly on the short-term. The absence of stability and security reconfigures labour markets and employment practices resulting in a reorientation of the subject in relation to work, career progression and company loyalty (Lloyd 2013). McDowell (2009) argues that interactive service work is flexible by nature; the direct service of consumer demand requires immediate delivery. As services cannot be stored and used later, the requirement for flexibility drives the sector, including the need for 24/7 service availability and provision. In Western Europe, North America and Australasia, the service economy accounts for three in four of all waged workers (McDowell 2009: 30). Given the recent proliferation of 'on-demand' working within the 'gig economy', the espousal of flexibility as intrinsically beneficial for both consumers and workers continues apace (Harvey et al 2016). Consumer capitalism has embedded modes of leisure such as shopping, gambling and the night-time economy within its circuits (Smith and Raymen 2016), all of which require, to one degree or another, flexible customer service operations. 
The character of service work may propel the demand for this flexibility yet it also reflects political, economic and ideological interests that rebalance the relationship between capital and labour (Harvey 2005). Systematic re-regulation of employment law has relocated power away from organised labour and the employee, which were ascendant in the middle third of the $20^{\text {th }}$ century, towards management and employers, seen as the innovators and wealth creators in an age of $21^{\text {st }}$ century entrepreneurial capitalism. By autumn 2016, UK legislation and employment law exhibited minimum statutory rights for employees with notable loopholes that equipped employers with techniques to circumvent formerly statutory obligations. Statutory Sick Pay (SSP) is a guaranteed employment right across all variety of contract, but to qualify, employees must be absent for four or more consecutive days (Statutory Sick Pay, $1^{\text {st }}$ September 2016). Workers off sick for one day can still be deducted pay, a regular practice observed in both retail and call centre work. Workers retain the right to request flexible working patterns that, according to the government, 'suit the employee's needs' (Flexible Working, $25^{\text {th }}$ October 2016). The request to work part-time, compressed hours, flexitime, annualised hours or staggered shifts, however, must be made formally and only following 26 weeks' continuous employment with a company. As much of the literature on the service economy illustrates, employee turnover rates suggest that six months' continuous work is often elusive (Shildrick et al 2012; Southwood 2011; Fenton and Dermott 2006). In the event the employee is eligible to submit an application, the employer can reject it on the grounds of business need. In observations and interviews with service economy workers, shifts affixed to weekly rotas became the responsibility of the employee to administer and change if required; managers habitually refused to accommodate shift changes and insisted the employee arranged to swap with a co-worker or perform the designated shift. Management refusal to bear responsibility for employee needs reflected an imposed so-called 'collegial ethos' in the workplace, which masked the shift in responsibility onto the employee and thus established an absence of security amongst employees expected to resolve their own problems, often without the support of superiors.

The reconfiguration of employment law dispenses freedom and flexibility for employers to navigate the circuits of consumer capitalism unencumbered by vociferous or onerous demands from labour. Firms can seize market opportunities without deferring to union voices. The flexibility agenda works almost entirely in favour of the employer; management practices that preach flexibility for workers in effect guarantee managers can employ staff on short-term contracts, zero-hours contracts, and parttime hours. Simultaneously, employees retain minimal rights and benefits, pay remains low, which enables management strategy and institutional practice to focus on 'just-in-time' service delivery or lean staffing models to maximise profit and demand higher productivity from employees. When 
retailers and food service industry representatives demand flexibility appropriate to the complexion of service work, they claim the right to employ working practices that best facilitate the bottom line. The inevitable reality of market-driven services beholden to shareholders or profit margins is the need to accumulate revenue; the normal function of the service economy requires employee relations and working conditions that may generate profit or growth but do so with disregard for job stability and security for service workers who engage in what Hatton (2011) calls the 'temp economy'.

An apparent acknowledgement of harms linked to job insecurity within the flexibility agenda engendered a reform movement headed under the term 'flexicurity' (see Wilthagen and Tros 2004). This 'theory-inspired policy model' promoted dynamism within competitive global markets through flexibility for employers but also ensured more and better jobs in a secure and socially cohesive labour market. The flexibility-security debate signals the poverty of left-liberal thought. It accepts the premise that dynamic, flexible, sustainable growth-led labour markets are essential and that any attempt to mitigate the harms of job insecurity must balance against the needs of the market.

Following the post-war settlement, a stable sense of working identity briefly appeared possible, sustained by a relative degree of job stability (Sennett 1999). The objective conditions of employment - job security, levels of pay, benefits, employment protections and skill level - ensured that the sense of historical progress felt through economic expansion and the proliferation of consumer markets was also recognised by the individual worker (Harvey 2005). Job security permitted one to plan for the future and furnished a durable sense of one's relative worth to society (Sennett 1999). Career paths and circumscribed routes from education into stable work were visible (Willis 1977). However, by the beginning of the $21^{\text {st }}$ century, the sustained absence of job security erodes both an immediate sense of constancy for employees likely to change jobs repeatedly (Southwood 2011) and those durable patterns and transitional markers young people use in order to make sense of their place in the world (Silva 2014). Service economy jobs are commonly described as 'entry-level' or 'McJobs' and this indicates the conventional and now archaic presumption that low-paid service work, or 'Saturday job' is the first step on an occupational ladder. Young men and women traditionally entered into service work before they exhibited the social mobility valorised by neoliberals and moved on to better paid and higher skilled work. For many, this transitional stepping stone is now elusive. The labour market conditions in many parts of the UK and USA are severely limited; public sector retrenchment, a lack of inward investment from the private sector and low diversity within labour markets all serve to limit the choices available in post-industrial regions unable to entice capital investment (Lloyd 2013). Within this context, the pull of the 'hidden economy' offers opportunities to derive pecuniary 
advantage in the shadow of legitimate means of subsistence. From working cash-in-hand to outright illicit activity, the systemic harms of job insecurity can propel some individuals into various forms of illegal activity.

Much of the youth transitions literature encompasses debates concerning parameters and boundaries within the life-course. Essentially, consideration of youth, adolescence and adulthood seeks clarification regarding the beginnings, endings and transitions between each phase of life (Furlong and Cartmel 2007; MacDonald and Marsh 2005; Arnett 2004; Hardgrove et al 2015; Roberts 2011; Silva 2014). Some youth scholars emphasise 'fragmented transitions' (see MacDonald and Marsh 2005) that denote intrinsic labour market mutability, but this should connect to a shift towards emphasis on more 'profitable' avenues for identification such as leisure and consumer circuits (Smith and Raymen 2016; Winlow and Hall 2013; Lloyd 2012). Silva (2014) observes that young people mark transitions to adulthood subjectively rather than using objective conditions such as stable employment or parenthood. Indicative of what Cederstrom and Spicer (2015) call a 'wellness syndrome' that places responsibility for well-being on the individual, Silva's cohort exhibits a turn towards subjectivity. Instability marks objective conditions (Standing 2011) - "broken homes", poor educational achievements, inconstant and low-paid jobs in the service economy, addictions, failed relationships, and criminal records, often gained through engagement in various forms of crime incentivised by the systemic harms which fracture legitimate labour markets. This ensures that objective conditions such as employment largely fail in the task of constructing a coherent sense of immutable progress through the life course. The absence of stability in, amongst other things, labour market conditions against which they can mark or recognise progression, results in the subject looking inwards for a sense of validation or achievement of adulthood.

\section{The Impact on Working Conditions}

Whilst the absence of job security engenders instability in the working lives of service economy employees, working conditions compound this anxiety. Management operation and organisational culture in late capitalist service work reveals capitalism's 'negation of the negation' (Winlow and Hall 2016). Taken from Hegel, the negation of the negation suggests that the gains made by labour noted above serve to negate the worst excesses of capitalism, as experienced in working practices. Capital's successful negation of the original negation is seen through the re-regulation of labour laws and the reorientation of working cultures and management practices that serve to create stressful, insecure and harmful conditions of employment. 
McDowell's (2009) contention that service economy work is demand-driven proposes a working environment configured towards 'just-in-time' service and accommodating consumer requirements effectively and efficiently. In a culture of instant gratification and aversion to waiting (Crary 2013), consumer capitalism places additional emphasis on the prompt resolution of customer service enquiries. Management practice and organisational culture across service economy workplaces combine lean staffing models with profitability; performance management and targets are standard features of service economy work such as retail and call centres (Lloyd 2013) whilst efficiency and speed combine with customer satisfaction through emotional labour in the night-time economy and food services industries (Leidner 1993). Whilst 'shop-floor' culture and the interaction between customers and employees are not wholly shaped by management (Williams 2006), they certainly influence it either tacitly by accepting working practices and cultural norms or by actively endorsing certain behaviours that facilitate the achievement of targets and profitability.

Assisted by regulations supporting capital growth and profit as economically beneficial, the power imbalance between employer and employee fosters working conditions and management practices that best ensure profitability but frequently negatively affect employee well-being. Targets and performance management create a culture whereby employees face work intensification, either electronically as in the call centre (Taylor and Bain 1999; Lloyd 2013), or through management compulsion as in retail (Lloyd forthcoming). Pressure flows down corporate hierarchies: store managers must meet targets to ensure profit is achieved, team leaders must ensure teams hit targets, and individual employees must suffer metrics-based performance management. This provokes an atmosphere whereby every customer is seen as an opportunity, every call a chance to improve figures, every table an opportunity for a tip. This application of affective, emotional or aesthetic labour (Hochschild 2003; Warhurst and Nickson 2007) suggests a vacuous or substanceless form of social interaction between two individuals, the customer and employee, focused on the self (Baudrillard 1993), and also creates a culture thoroughly compelled with the need to maximise profitability and achieve goals and targets.

The call centre literature establishes the work intensification and target-driven nature of an 'assemblyline in the head' as responsible for stressful working conditions and physical or emotional burnout (Lloyd 2013; Deery et al 2010; Wegge et al 2010). Many of these practices are also visible in retail; subjects attest to the target-driven culture underpinning management coercion to approach customers and deploy an extensive range of techniques and emotional labour to close a sale (see Lloyd forthcoming). Meanwhile, the demand-driven reality of service work inevitably creates slow intervals, 
experienced as mind-numbing periods of time where the 'tyranny of the clock' asserts itself; shifts are seemingly interminable. This dichotomy between intense work periods driven by management imperatives and intervals of slow, boring down time, characterise many service economy jobs. Of course, should the slow periods persist, for example due to an economic downturn, management soon look to cut costs and conserve profit margins by reducing staffing levels.

Zero-hours and temporary contracts offer management the flexibility to staff according to customer demand and peak times, offering shifts during busy periods without any obligation to dispense shifts during quiet spells. The flexibility associated with these contracts works entirely in the employer's favour, while employees are seldom in the position to willingly refuse hours. Zero-hours contracts are also inadvertently divisive; an employee can suddenly find shifts available as a consequence of coworkers being ill, falling out of favour, someone being let go. In a culture of competitive individualism, zero-hours contracts reflect this as co-workers can become competition for vital resources. Temporary contracts afford flexibility to employers, as do employment agencies, nevertheless the employee experiences this as insecure and uncertain. Employers are often candid about the limited prospect of contract extensions but taking on staff to cover peak periods inevitably leads to hope for a permanent position. While some temporary positions do become permanent, many do not.

Stressful conditions, insecure contracts, targets and management pressure, coupled with customerfacing functions frequently accompanied by problematic interactions with dissatisfied customers, are the daily reality of service economy jobs. Levels of pay seldom reflect the hard work, stress and anxiety accompanying these insecure and difficult forms of employment. Employment law guarantees a national minimum wage to all employed on a contract (from permanent to zero-hours) but despite the UK government declaring commitment to a 'living wage', this is only available to over $25 \mathrm{~s}$. Pay levels are supplemented by bonuses derived from realization of targets and performance management which ensures an instrumental, competitive individualism pervades the workplace as co-workers chase sales and targets in order to bolster meagre wages. Given policy analysis suggesting that the living wage still falls short of securing a reasonable standard of living, assuring bonuses through performance targets, overtime (often paid at basic rate), and working more than one job become normalised practice within the service economy.

Whilst the use of targets is not limited to the service economy, pay levels remain above the legal mandatory requirement and working conditions are often less physically hazardous than other forms of employment. However exacting conditions, low pay and management practices devised to 
maximise revenue rather than well-being combine to produce difficult and harmful working environments. High levels of sickness, high staff turnover and mounting problems of mental ill health within low-paid forms of service work are manifestations of problematic employment conditions (Lloyd 2013). In today's service economy, employees lack any genuine protection from work intensification, management demand for targets, performance management, emotional labour, the insecurity and instability linked to flexible working patterns and low pay, but they experience it as 'normal'. In a culture of competitive individualism, co-workers offer little consolation against the drudgeries of work. The absence of protection from demanding working conditions engenders further harm, whilst this negativity transmutes the culture of the workplace and interpersonal relations between co-workers.

\section{The Absence of Moral Responsibility}

It is equally important to examine subjects willing to inflict harm on others (Hall and Winlow 2015). Those individuals are discernible across a range of contexts but are most noticeable in research conducted on violent and entrepreneurial criminals (Ellis 2016; Hall et al 2008). Hall's (2012) concept of 'special liberty' delineates an individual embedded within the socio-symbolic structures of neoliberal ideology; epitomising the competitive individualism, envy and self-interest fuelling consumer capitalism, the individual possessing special liberty is convinced of their right to maximise their market share and keep rivals from threatening their position, using any means necessary. This is also evident within the service economy.

Some managers, team leaders, and colleagues evince a willingness to visit harm on co-workers and subordinates in order to maximise an opportunity or preserve their position within the organisational hierarchy. Not all harm and violence is physical, although in the extended ethnography underpinning this chapter, physical violence did occur on occasion. The two most notable examples are 'stealing sales' and management bullying. Stealing sales is a practice that transpires frequently in retail. This occurs in several ways and essentially entails temporary or new and inexperienced sales people cultivating a sale, then experienced colleagues interjecting to 'steal' the sale and processing it under their employee number rather than the colleague originally responsible for generating the sale.

In the context of target-driven sales, performance management and bonuses linked to volume and quality of sales, the seemingly innocuous practice of 'stealing sales' becomes more invidious. Temporary sales personnel, usually employed over Christmas, compete for scarce permanent contracts and must display a positive attitude, willingness to sacrifice for the company, and good sales 
figures. Losing sales adversely impacts their sales targets and therefore their chances to secure permanent work. Those permanent colleagues in possession of special liberty seek to protect their own position and will deliberately harm temporary or inexperienced colleagues by stealing sales. Under pressure to meet their own targets, no justification is necessary for inflicting this harm. In a culture that actively encourages high-pressure, target-driven practices, management often approve of employees seen as proactive and capable and either accept or turn a blind eye to their harmful behaviour.

The second form of special liberty is perceptible in management practices within the service economy. Within this culture, team leaders and managers in possession of special liberty will exhibit behaviours that assert their authority over employees in a way that descends into bullying as a way to reinforce their own fragile position. Interviewees and observations highlighted instances where managers and team leaders victimised co-workers, often with the implicit acquiescence or involvement of other colleagues and managers either because of envy, fear of competition from high-performing sales-staff, or simple personality clashes. With managers under intense pressure over targets, some inflict cruel and lasting harms on employees under the auspices of business need, but some inflict harms simply because they can. Employees, largely ignorant of the few rights they do possess, quietly accept this treatment until they leave or suffer emotional or physical damage (see Lloyd forthcoming).

The harms of special liberty reflect another absence, the absence of any sense of ethical obligation or moral duty to the other (Smith and Raymen 2016, Hall and Winlow 2015). The embedded ideological contours of consumer capitalism and neoliberal governance promote competitive individualism through social mobility, competition, meritocracy, self-interest, personal responsibility for well-being and a winner-takes-all attitude (Smith and Raymen 2016, Winlow and Hall 2013). Popular culture exhibits these values. This libidinal energy propels consumer capitalism and advances a culture increasingly devoid of the pro-social; the idea of an ethical obligation or any sense of moral duty to a co-worker or employee is perceived as naive. For some subjects, possessing special liberty allows them to navigate the insecure and unstable waters of contemporary capitalism, maximising their relative position by inflicting harms on others, acting as a bailiff, using their position to secure material, symbolic and emotional sustenance by removing it from co-workers. The absence of an ethical duty to the other signals a wider negative transformation of the workplace; absence is not merely a causative component of harm but also creates space filled by negativity - a negativity that reconstructs workplace culture, management practice and interpersonal relations. 


\section{Conclusion}

An ultra-realist account of the service economy pinpoints the harms that emanate from a multitude of crucial absences. The absence of stability in service economy labour stems from the political economic turn associated with neoliberal restructuring of labour markets inclined towards capital and the employer and at the expense of employee protection. The ideological change from 'security' to 'flexibility' reveals the generative core of capital eroding employee protections and benefits secured since the post-war settlement. In the absence of well-paid, secure, skilled and stable employment, the service economy is an insecure, low-paid and 'flexible' form of labour where employees have few rights and little recourse to challenge the imparities and injustices of the workplace. Work intensification strategies, relentless pressure to discharge successful emotional labour, and targets linked to performance management epitomise organisational practices that fill the voids which stem from these absences. The use of insecure, temporary and zero-hours contracts helps to keep costs low and ensures maximum flexibility for employers while the employee is left with insecurity and anxiety over the possibility of finding a steady, stable career path in order to pay bills and feed families. The absence of stability erodes the consolations that make difficult working practices bearable. Capital's 'negation of the negation' (Winlow and Hall 2016) ensures that service economy employees are embedded within its circuits; immediate pressures of bills and mortgages take precedence over timeconsuming struggles to secure fair practices and pay rises, particularly in light of inadequate employee protection and rights. Meanwhile capitalism offers consolations in the very consumer markets that service economy employees facilitate. Finally, the absence of an ethical duty or moral obligation to the other leads some to clothe themselves in a special liberty (Hall 2012) which prefigures a willingness to impose harm on co-workers in order to maximise market shares, boost sales figures and reach targets in order to achieve pay rises. The competitive individualism endemic in consumer capitalist culture plays out on the sales floor, either visibly or surreptitiously, as employees jostle for limited position and rewards. These harms are multitude and visible across the service economy, not simply in the most notable examples raised in media reports.

Perhaps the most problematic absence relates to the symbolic efficiency of neoliberalism (Winlow and Hall 2013). After decades of deep structural change reconfigured political economy, transposed and restructured organisational culture and working practices, redefined employment law in favour of employers and created vast numbers of low-paid insecure jobs that facilitate consumer capitalism's material and symbolic realities, neoliberalism's symbolic efficiency diminished significantly following the financial crisis (Žižek 2010). No longer a consistent set of signs and symbols, markers to root the individual within the social and afford a measure of sense and meaning to the world, the limits of 
neoliberal ideology become palpable and viscerally felt within marginalised communities, those stuck in the sorts of work described here, and the increasingly imperilled middle class. The fantasy of neoliberalism, upward social mobility for the hard-working, has vanished for a large section of the population. Years of low-paid, stressful, insecure work in service jobs marked by instability, targets and management demand fails to yield any sort of stable, meaningful existence or equitable standard of living (Lloyd 2013) and brings the intransitive realm of depth structures within the practical knowledge and realities of a significant segment of the population who realise that political narratives and ideological exhortations no longer speak to their experience of the social world. The absence of a symbolically efficient ideology begets further instability and harm at the material, symbolic and psycho-social level. This is the fundamental harm, the systemic violence of capitalism. 


\section{Bibliography}

Arnett, J.J. (2004) Emerging Adulthood. New York: Oxford University Press.

Badiou, A. (2009) The Century. Cambridge: Polity Press.

Baudrillard, J. (1993) The Transparency of Evil. London: Verso.

Bhaskar, R. (2010) Reclaiming Reality. London: Routledge.

Cederstrom, C. and Spicer, A. (2015) The Wellness Syndrome. Cambridge: Polity.

Collier, A. (1994) Critical Realism: An Introduction to Roy Bhaskar's Philosophy. London: Verso.

Crary, J. (2013) 24/7: Late Capitalism and the Ends of Sleep. London: Verso.

Deery, S., Iverson, R. and Walsh, J. (2010) “Coping strategies in call centres: Work intensity and the role of coworkers and supervisors" in British Journal of Industrial Relations. 48(1) 181-200.

Ellis, A. (2016) Men, Masculinities and Violence: An Ethnographic Study. London: Routledge.

Fenton, S. and Dermott, E. 2006. Fragmented careers? Winners and losers in young adult labour markets. Work, Employment and Society. 20(2), 205-221.

Flexible Working (25 ${ }^{\text {th }}$ October 2016) The Crown Copyright, Accessed on: $17^{\text {th }}$ February 2017, Available at: https://www.gov.uk/flexible-working/overview

Furlong, A. and Cartmel, P. (2007) Young people and social change: new perspectives. ( $2^{\text {nd }}$ Ed.) Maidenhead: Open University Press.

Hall, S., Winlow, S. and Ancrum, C. (2008) Criminal Identities and Consumer Culture. Oxford: Willan.

Hall, S. (2012) Theorizing Crime and Deviance: A New Perspective. London: Sage.

Hall, S. and Winlow, S. (2015) Revitalizing Criminological Theory: Towards a New Ultra-Realism. London: Routledge.

Hardgrove, A., McDowell, L. and Rootham, E. (2015) “Precarious lives, precarious labour: Family support and young men's transitions to work in the UK" in Journal of Youth Studies. 18(8) 1057-1076.

Harvey, D. (2005) A Brief History of Neoliberalism. Oxford: University Press.

Harvey, G., Rhodes, C., Vachhani, S.J. and Williams, K. (2016) “Neo-villeiny and the service sector: The case of hyper flexible and precarious work in fitness centres" in Work, Employment and Society. Online first http://wes.sagepub.com/content/early/2016/03/18/0950017016638023.full.pdf+html

Hatton, E. (2011) The Temp Economy. Philadelphia: Temple University Press.

Hillyard, P. and Tombs, S. (2004) “Beyond Criminology?" in Hillyard, P., Pantazis, C., Tombs, S. and Gordon, D. (Eds.) Beyond Criminology: Taking Harm Seriously. London: Pluto Press.

Hochschild, A. R. (2003) The Managed Heart. London: University of California Press.

Horsley, M. (2015) The Dark Side of Prosperity. Farnham: Ashgate.

Johnston, A. (2008) Žižek's Ontology: A Transcendental Materialist Theory of Subjectivity. Northwestern: University Press. 
Kalleberg, A.L. (2009) "Precarious work, insecure workers: Employment relations in transition" in American Sociological Review. 74(1) 1-22.

Leidner, R. (1993) Fast Food, Fast Talk. London: University of California Press.

Lloyd, A. (2012) "Working to Live, Not Living to Work: Work, leisure and youth identity among call centre workers in North East England" in Current Sociology. 60(5) 619-635.

Lloyd, A. (2013) Labour Markets and Identity on the Post-Industrial Assembly Line. Basingstoke: Ashgate.

Lloyd, A. (2017a) "Ideology at Work: Reconsidering ideology, the labour process and workplace resistance" in International Journal of Sociology and Social Policy. 37(5/6)

Lloyd, A. (2017b) "Efficiency, productivity and targets: The gap between rhetoric and reality" in The British Journal of Sociology. (under consideration).

Lloyd, A. (forthcoming) The Harms of Work: An Ultra-Realist Account of the Service Economy. (book proposal under consideration).

MacDonald, R. and Marsh, J. (2005) Disconnected Youth: Growing up in Britain's poor neighbourhoods. Basingstoke: Palgrave Macmillan

McDowell, L. (2009) Working Bodies: Interactive Service Employment and Workplace Identities. Chichester: Wiley-Blackwell.

Pemberton, S. (2015) Harmful Societies: Understanding Social Harm. Bristol: Policy Press.

Roberts, S. (2011) “Beyond 'NEET' and 'Tidy' pathways: Considering the 'missing middle' of youth transition studies' in Journal of Youth Studies. 14(1) 21-39.

Scott, S. (2017) Labour Exploitation and Work-Based Harm. Bristol: Policy Press.

Sennett, R. (1999) The Corrosion of Character. London: WW Norton \& Company.

Shildrick, T. et al (2012) Poverty and Insecurity. Bristol: Policy Press.

Silva, J.M. (2014) Coming Up Short. Oxford: University Press.

Smith, O. and Raymen, T. (2016) "Deviant leisure: A criminological perspective" in Theoretical Criminology. Online first at

http://tcr.sagepub.com/content/early/2016/08/10/1362480616660188.full.pdf+html

Southwood, I. (2011) Non-Stop Inertia. Winchester: Zero.

Standing, G. (2011) The Precariat. London: Bloomsbury.

Statutory Sick Pay (SSP) (1 $1^{\text {st }}$ September 2016) The Crown Copyright, Accessed on: $17^{\text {th }}$ February 2017, Available at: https://www.gov.uk/employers-sick-pay

Streeck, W. (2016) How Will Capitalism End? London: Verso.

Taylor, P. and Bain, P. (1999) “'An assembly line in the head': Work and employee relations in the call centre" in Industrial Relations Journal. 30(2) 101-117. 
Tombs, S. (2004) "Workplace injury and death: Social harm and the illusions of law" in Hillyard, P., Pantazis, C., Tombs, S. and Gordon, D. (Eds.) Beyond Criminology: Taking Harm Seriously. London: Pluto Press. Tombs, S. and Whyte, D. (2007) Safety Crimes. Cullompton: Willan.

Warhurst, C. and Nickson, D. (2007) "Employee experience of aesthetic labour in retail and hospitality" in Work, Employment and Society. 21(1) 103-120.

Wegge, J., van Dick, R. and von Bernstorff, C. (2010) "Emotional dissonance in call centre work" in Journal of Managerial Psychology. 25(6) 596-619.

White, R.D. and Heckenberg, D. (2014) Green Criminology: An Introduction to the Study of Environmental Harm. London: Routledge.

Whitehead, P. (2015) Reconceptualising the Moral Economy of Criminal Justice. Basingstoke: Palgrave Pivot.

Whitehead, P. and Hall, S. (2017) "Generative core and regulatory jacket" (work in progress)

Williams, C.L. (2006) Inside Toyland. London: University of California Press.

Willis, P. (1977) Learning to Labour. Farnham: Ashgate.

Winlow, S. and Hall, S. (2013) Rethinking Social Exclusion. London: Sage.

Winlow, S. and Hall, S. (2016) "Realist Criminology and its Discontents" in International Journal for Crime, Justice and Social Democracy. 5(3) 80-94.

Withagen, T. and Tros, F. (2004) "The concept of 'flexicurity': A new approach to regulating employment and labour markets" in Transfer: European Review of Labour and Research. 10(2) 166-186.

Yar, M. (2012) "Critical criminology, critical theory and social harm" in Hall, S. and Winlow, S. (Eds.) New Directions in Criminological Theory. London: Routledge.

Žižek, S. (2000) The Ticklish Subject. London: Verso.

Žižek, S. (2008) Violence. London: Profile Books.

Žižek, S. (2010) Living in the End Times. London: Verso. 